\title{
Towards the Development of a Lodging Service Recovery Strategy
}

\author{
John W. O’Neill \\ Anna S. Mattila
}

\begin{abstract}
This article presents findings from a survey of 613 hotel guests and indicates that guests' overall satisfaction regarding service failure and service recovery are higher when they believe that service failure is unstable and recovery is stable. Moreover, guests indicate they are more likely to return to the same hotel when they believe that service failure is unstable and recovery is stable. Finally, our results indicate that guests are actually more satisfied with their guest room when they believe that recovery is stable. Implications for managers' strategies are discussed. [Article copies available for a fee from The Haworth Document Delivery Service: 1-800-HAWORTH. E-mail address: <docdelivery@ haworthpress. com> Website: <http://www.HaworthPress.com> () 2004 by The Haworth Press, Inc. All rights reserved.]
\end{abstract}

KEYWORDS. Service failure, service recovery, hotel, strategy

John W. O'Neill, PhD, is Assistant Professor, School of Hotel, Restaurant and Recreation Management, The Pennsylvania State University, 233 Mateer Building, University Park, PA 16802-1307 (E-mail: jwo3@psu.edu).

Anna S. Mattila, PhD, is Assistant Professor, School of Hotel, Restaurant and Recreation Management, The Pennsylvania State University, 224 Mateer Building, University Park, PA 16802-1307 (E-mail: asm6@psu.edu).

Address correspondence to John W. O'Neill at the above address.

The authors gratefully acknowledge Sookyung Kim's assistance with data entry and management.

An earlier version of this paper was presented at the Annual CHRIE Convention in Orlando, Florida in August 2002 (Best Paper Award).

Journal of Hospitality \& Leisure Marketing, Vol. 11(1) 2004
http://www.haworthpress.com/store/product.asp?sku=J150
( 2004 by The Haworth Press, Inc. All rights reserved.

10.1300/J150v11n01_04 


\section{INTRODUCTION}

Service recovery is now recognized as a significant determinant of customer satisfaction and loyalty (Fornell \& Wernerfelt, 1987; Smith \& Bolton, 1998; Tax \& Brown, 1998; Smith et al., 1999). Consequently, many hospitality operators have developed service recovery policies to revive the endangered relationship with dissatisfied guests (e.g., Liu, Warden, Lee \& Huang, 2001). In fact, most service organizations, including hotels, are forced to pay attention to service recovery because lingering dissatisfaction is not limited to the incident or customer at hand (Brown, 1997). Previous research indicates that upset customers will tell ten to twenty people about their bad experience with a service operation (Zemke, 1999). Despite its managerial importance, scholarly research in service recovery remains in its infancy stage (Johnston \& Fern, 1999).

The primary goal of this study is to explore the role of explanations in mitigating the negative effects of service failures. More specifically, we investigate how hotel guests' stability attributions influence their post-recovery service perceptions and return intentions in a context of hotel overbooking. Our goal is to examine whether the way in which overbooking information is communicated to the guest influences his/her satisfaction with the hotel. To that end, we manipulate the stability of service failure (i.e., the frequency of overbooking) and the stability of the service recovery (the likelihood of upgrading to a suite, should overbooking occur in the future) in a hypothetical consumption experience with 613 actual hotel guests originating from 30 different countries.

\section{LITERATURE REVIEW AND HYPOTHESES DEVELOPMENT}

When service goes awry, guests are concerned with explanations for service failure (Weiner, 2000). Attribution theory assumes that people are rational information processors whose actions are influenced by causal inferences (Folkes, 1984). Wiener (1980) developed a categorization scheme that classifies causes for product failures by three dimensions: locus of control, stability, and controllability. Locus of control captures whether the failure was consumer-related or caused by external factors (Folkes, 1984). The stability dimension assesses the degree to which a cause is seen as relatively permanent (Folkes, 1988), while controllability refers to the degree to which a cause was under the firm's or the service provider's volitional control (Taylor, 1994). 
The focus of the present investigation is on the stability of service failures and recovery efforts. Prior research has established that stability attributions are important in service failure situations (e.g., Smith \& Bolton, 1988). In addition, Folkes' (1984) qualitative study with restaurant customers showed that 36 percent of the respondents attributed unpalatable food to stable causes. Moreover, the results from Folkes et al.'s (1987) field study of airline delays showed that passengers' stability inferences influence their repatronage intentions. In Smith and Bolton's (1998) study, the impact of stability attributions on cumulative satisfaction was limited to a restaurant (student) sample. McCollough (2000) reported that overbooking is a dangerous strategy because even superior recovery might not overcome the negative consequences of low harm failures. The author showed that for the recovery effect to occur, customers needed to feel confident that overbooking was unstable (i.e., not a company policy) and the recovery was stable (upgrading to a better room can be expected in the future, should the problem occur).

Recent research in service recovery suggests that consumers have expectations not only for the initial service encounter but also for service recovery and service failures (e.g., Miller et al., 2000). Consumer expertise or familiarity with a product category is directly linked to the concept of expectations (Oliver, 1997). Compared to novice consumers, frequent travelers have more accurate expectations for the frequency of overbooking in the hotel industry. Moreover, these experienced product users have realistic expectations for service recovery. In other words, their perceptions of service failures and recovery outcomes might be different from consumers with relatively low levels of familiarity with overbooking practices. For instance, forty percent of respondents (hotel guests) in Levesque and McDougall's (2000) study indicated that they had been victims of overbooking. Given the importance of product expertise in expectation formation processes, we argue that using student samples (as was the case with previous research in service recovery, e.g., Smith \& Bolton, 1998; McCollough, 2000) may taint the results of such a study. Consequently, we put forth the following hypotheses:

Hypothesis 1: A hotel guest's overall satisfaction and service quality assessments will be higher (lower) when she/he believes that the service failure is unlikely (likely) to happen again.

Hypothesis 2: A hotel guest's overall satisfaction and service quality assessments will be higher (lower) when she/he believes that the service recovery is stable (unstable). 
In addition to the robust satisfaction-behavioral intent link (e.g., Tam, 2000), prior research in consumer behavior shows that consumer attributions for product- or service-related problems influence their postconsumption behaviors (Richins, 1983). For example, Folkes et al. (1987) showed that travelers were less willing to repurchase an airline ticket when they attributed delays to stable causes. Accordingly, we hypothesize that stability attributions should influence the guest's return intentions. Therefore, we propose the following:

Hypothesis 3: A hotel guest's return intent will be higher (lower) when she/he believes that the service failure is unlikely (likely) to happen again.

Hypothesis 4: A hotel guest's return intent will be higher (lower) when she/he believes that the service recovery is stable (unstable).

Previous work in consumer behavior shows that attributions influence consumer preferences for redress (Folkes et al., 1984). In that study, consumers were more willing to accept product exchange as a compensation method when they attributed the failure to unstable causes. Conversely, stable attributions led to preference for refunds. We extend this line of reasoning to service recovery outcomes. Unlike in McCollough's (2000) study with undergraduate students, we argue that guest satisfaction with the recovery outcome (room upgrade) depends on the consumer's stability attributions. Knowing that the same compensation method will be available in the future should increase the guest's overall confidence in the hotel. As a result, satisfaction with the recovery outcome should be enhanced. Conversely, increased uncertainty about future outcomes associated with unstable recovery method (Weiner, 1980), should have a negative impact on guest perceptions. Feeling that the room upgrade was based on luck should reduce satisfaction with the compensation method. Hence, we hypothesize the following:

Hypothesis 5: A guest's satisfaction with the compensation method (an upgraded room) will be higher (lower) when she/he believes that the service recovery is stable (unstable).

\section{RESEARCH METHODOLOGY}

This study used scenarios developed by McCollough (2000) to test our research hypotheses. The use of scenarios has been established as a 
valid methodology for investigating service quality and service failure/recovery in the hospitality literature (e.g., Mattila, 1999). Furthermore, service failures and recoveries are common in the lodging industry (Mount \& Mattila, 2000). As a result, we expected real users (actual hotel guests) to find service failure (i.e., their reserved guest room not being available) and service recovery (i.e., being upgraded to a suite) to be both realistic and believable. Moreover, upgrading the guest to a superior guest room is a frequently encountered recovery technique in the lodging industry (McCollough, 2000).

Our study involved a $2 \times 2$ between-subjects design, with stable and unstable failure attributions, and stable and unstable recovery attributions. All four scenarios presented a failure in which a guest's reserved room, which was a basic, economy room, was not available due to the hotel being overbooked. In all four scenarios, the recovery technique of the hotel front office was kept constant (i.e., upgrading the guest to an available suite). In the two stable failure scenarios, the failure was depicted as common due to the hotel's policy of overbooking. Conversely, in the two unstable failure scenarios, the failure was pictured as uncommon due to the hotel's policy of not overbooking. In the two unstable recovery scenarios, the hotel was portrayed as generally being overbooked with no extra rooms available, and upgrading the guest to a suite was depicted as an atypical circumstance due to a cancellation. With stable recovery, the hotel was described as usually having many extra guestrooms available. To reiterate, in all four conditions, the recovery was the same upgrade to a suite, i.e., a positive recovery outcome.

Prior to their exposure to stimulus information, participants were asked to provide the name and location of a hotel where they had stayed during the past year. Next, they were asked to evaluate the service quality of the hotel based on their actual experiences there (based on three survey questions), and were asked how likely they would be to return to the hotel in the future (based on one question) on a scale of 1 to 5. Then, participants were asked to read a scenario, imagining that the encounter had occurred at the hotel where they had named in the previous question. This procedure is similar to that employed by Smith and Bolton (1998) and is a methodology that assures accurate pre-scenario attitudes and eliminates any necessity to manipulate or impose pre-scenario attitudes. Finally, participants were asked to evaluate post-scenario service quality (based on three questions), outcome satisfaction (based on three questions), general satisfaction (based on three questions), and intent to 
return (based on one question). A sample of the unstable failure/stable recovery survey is included in the Appendix.

\section{SAMPLE AND MEASURES}

The sample was composed of 613 hotel guests originating from 30 different countries. Most respondents were from the U.S., while the most common nationalities of those respondents who were not from the U.S. were Canada (14 respondents), Jamaica (10 respondents), Aruba (5 respondents), and England (5 respondents). The mean age of respondents was approximately 33 years old, with a range of 19 to 75 . A respondent profile is presented as Table 1.

Trained graduate students, who randomly assigned potential respondents into the four experimental conditions, and who administered surveys in person, randomly selected participants. Due to some missing responses for some items, the sample size varies slightly by analysis. A total of 151 respondents participated in the stable failure/stable recovery scenario, 158 participants were in the unstable failure/unstable recovery scenario, 149 respondents were in the unstable failure/stable recovery scenario, and 155 respondents were in the stable failure/unstable recovery scenario.

Existing scales were used wherever possible (see appendix for the actual scales). Confirmatory factor analysis (CFA) using structural equation modeling (SEM) was performed to examine the reliability and validity of the outcome satisfaction, overall satisfaction and service quality scales. The results from the CFA show that the item reliabilities for all scales were above 0.50 , hence suggesting adequate construct validity. Moreover, the model achieved a good fit, with a goodness-of-fit index (GFI) of 0.97, and an adjusted goodness-of-fit index (AGFI) of 0.95. The root mean square error of approximation (RMSEA) was 0.06, demonstrating an acceptable fit (Schumacker \& Lomax, 1996). The $\chi^{2}$ value

TABLE 1. Respondent Profile

Variable
\begin{tabular}{|llll|}
\hline Sex & male $=284(46.4 \%)$ & female $=328(53.5 \%)$ & $\mathrm{n}=612$ \\
\hline Nationality & U.S. $=539(87.9 \%)$ & non-U.S. $=74(12.1 \%)$ & $\mathrm{n}=613$ \\
\hline Age & mean $=32.9$ & std. dev. $=12.0$ & $\mathrm{n}=598$ \\
\hline
\end{tabular}


was significant at $76.8(\mathrm{df}=24, \mathrm{p}<0.05)$. However, as the sample size increases (generally above 200 ), the $\chi^{2}$ test has a tendency to indicate a significant probability level (Schumacker \& Lomax, 1996, pp. 124-125). In this present study, the large sample of 613 respondents might have contributed to the significant $\chi^{2}$ value. However, interpreted alongside the other goodness-of-fit statistics, the model fit appears to be very acceptable.

The internal reliability of all scales exceeds the conventional minimum of .70 (Rosenthal \& Rosnow, 1991). Specifically, the three questions making up the pre-scenario service quality factor resulted in a Coefficient Alpha of .91, the three questions making up post-scenario service quality had an Alpha of .91, the three questions comprising the overall satisfaction factor had an Alpha of .92, and the three questions comprising the general satisfaction factor had an Alpha of .89.

\section{FINDINGS}

The use of a MANCOVA procedure incorporating outcome satisfaction, overall satisfaction, service quality and return intent as multiple response variables was justified because these measures correlated positively with each other (for correlation coefficients between the response measures, please see Table 2). Since prior experiences with the hotel might bias the consumer's future evaluations, the subject's pre-exposure service quality assessment was run as a covariate in the data analysis.

The mean ratings by failure and recovery attribution for all four response measures are presented in Table 3. The Wilks lambda F approxi-

TABLE 2. Correlation Coefficients Between Outcome Satisfaction, General Satisfaction, Post-Scenario Service Quality, and Return Intent

\begin{tabular}{|lcccc|}
\multicolumn{1}{l}{} & $\begin{array}{l}\text { Outcome } \\
\text { Satisfaction }\end{array}$ & $\begin{array}{l}\text { General } \\
\text { Satisfaction }\end{array}$ & $\begin{array}{l}\text { Post Scenario } \\
\text { Service Quality }\end{array}$ & Return Intent \\
\hline Outcome Satisfaction & 1.000 & & & \\
\hline General Satisfaction & $0.569^{*}$ & 1.000 & & \\
\hline Post Scenario Serv. Qual. & $0.506^{*}$ & $0.835^{*}$ & 1.000 & \\
\hline Return Intent & $0.441^{*}$ & $0.768^{*}$ & $0.799^{*}$ & 1.000 \\
\hline
\end{tabular}

${ }^{*}$ correlation is significant at the .01 level 
TABLE 3. Response Variable Means by Failure and Recovery Attribution

\begin{tabular}{|ccccccccc|}
\multicolumn{1}{c}{} & \multicolumn{2}{c}{$\begin{array}{c}\text { Post-Scenario } \\
\text { Service Quality }\end{array}$} & \multicolumn{2}{c}{$\begin{array}{c}\text { General } \\
\text { Satisfaction }\end{array}$} & \multicolumn{2}{c}{ Return Intent } & \multicolumn{2}{c}{$\begin{array}{c}\text { Outcome } \\
\text { Satisfaction }\end{array}$} \\
& $\begin{array}{c}\text { Stable } \\
\text { recovery }\end{array}$ & $\begin{array}{c}\text { Unstable } \\
\text { recovery }\end{array}$ & $\begin{array}{c}\text { Stable } \\
\text { recovery }\end{array}$ & $\begin{array}{c}\text { Unstable } \\
\text { recovery }\end{array}$ & $\begin{array}{c}\text { Stable } \\
\text { recovery }\end{array}$ & $\begin{array}{c}\text { Unstable } \\
\text { recovery }\end{array}$ & $\begin{array}{c}\text { Stable } \\
\text { recovery }\end{array}$ & $\begin{array}{c}\text { Unstable } \\
\text { recovery }\end{array}$ \\
\hline $\begin{array}{c}\text { Stable } \\
\text { Failure }\end{array}$ & $\begin{array}{c}3.85 \\
\left(0.88^{*}\right)\end{array}$ & $\begin{array}{c}3.13 \\
\left(1.06^{*}\right)\end{array}$ & $\begin{array}{c}3.98 \\
\left(0.89^{*}\right)\end{array}$ & $\begin{array}{c}3.31 \\
\left(1.10^{*}\right)\end{array}$ & $\begin{array}{c}3.76 \\
\left(1.19^{*}\right)\end{array}$ & $\begin{array}{c}2.96 \\
\left(1.35^{*}\right)\end{array}$ & $\begin{array}{c}4.56 \\
\left(0.69^{*}\right)\end{array}$ & $\begin{array}{c}4.47 \\
\left(0.73^{*}\right)\end{array}$ \\
\hline $\begin{array}{c}\text { Unstable } \\
\text { Failure }\end{array}$ & 4.34 & 3.77 & 4.38 & 3.87 & 4.26 & 3.74 & 4.71 & 4.54 \\
$\left(0.74^{*}\right)$ & $\left(0.94^{*}\right)$ & $\left(0.78^{*}\right)$ & $\left(0.86^{*}\right)$ & $\left(0.94^{*}\right)$ & $\left(1.16^{*}\right)$ & $\left(0.54^{*}\right)$ & $\left(0.74^{*}\right)$ \\
\hline
\end{tabular}

*std. dev.

mations for failure and recovery attributions were significant (Wilks lambda $=.901$ for failure and Wilks lambda $=.861$ for recovery effect, $\mathrm{p}<.001$ for both). The interaction effect was insignificant. The means and standard deviations for our response variables are presented in Table 3 .

Univariate F-tests for recovery attribution were significant at $\mathrm{p}<.05$ for all four response measures. For service quality, $F=85.29, \mathrm{p}<.001$; for overall satisfaction, $\mathrm{F}=67.51, \mathrm{p}<.01$; for return intent $\mathrm{F}=55.79$, $\mathrm{p}<.01$, and finally, for outcome satisfaction, $\mathrm{F}=3.07, \mathrm{p}<.05$. When failure was stable (i.e., likely to happen again), the mean rating for post-scenario service quality was 3.49 (3.85 with stable recovery and 3.13 with unstable recovery), whereas when failure was unstable (i.e., unlikely to happen again), the mean rating for post-scenario service quality increased to 4.05 (4.34 with stable recovery and 3.77 with unstable recovery). The same pattern was observed for our general satisfaction scale. When failure was stable, the mean rating for general satisfaction was 3.64 (3.98 with stable recovery and 3.31 with unstable recovery), whereas when failure was unstable, the mean rating for general satisfaction increased to 4.12 (4.38 for stable recovery and 3.87 for unstable recovery). Taken together, these results support Hypothesis 1.

When recovery was stable, the mean rating for outcome satisfaction was 4.63, whereas in an unstable recovery condition the mean was 4.52. The guests who believed that failure was unstable and recovery was stable (mean $=4.71)$ were significantly more satisfied with the compensation method than their counterparts in the stable failure and unstable recovery condition $($ mean $=4.47$ ). This finding provides support for Hypothesis 5. With return intent, the mean rating for return intent was 3.36 when failure was stable. Conversely, when the guest perceived the 
failure as unstable, the mean return intent increased to 3.99. This finding supports Hypothesis 3.

For failure attributions, the univariate F-tests were significant for service quality, overall satisfaction and return intent, $\mathrm{F}=55.89, \mathrm{~F}=39.85$ and $\mathrm{F}=42.91$, respectively, $\mathrm{p}<.001$. When recovery was stable, the mean rating for post-scenario service quality was 4.09 (3.85 with stable failure and 4.34 with unstable failure), whereas when recovery was unstable, the mean rating for post-scenario service quality decreased to 3.45 (3.13 with stable failure and 3.77 with unstable failure). The same pattern was repeated with general satisfaction. When recovery was stable, the mean rating for general satisfaction was 4.18 (3.98 with stable failure and 4.38 with unstable failure), whereas when failure was unstable, the mean rating for general satisfaction dropped to 3.60 (3.31 with stable failure and 3.87 with unstable failure). Therefore, Hypothesis 2 was supported.

With stable recovery, the mean rating for return intent was 4.01, whereas when failure was unstable, the mean rating dropped to 3.35. The guests who were most likely to return believed that failure was unstable and recovery was stable (mean $=4.26$ ), while the guests who were least likely to return believed that failure was stable and recovery was unstable $($ mean $=2.96)$. These results provide support for Hypothesis 4 .

The attribution framework postulates that consumers are concerned with explanations for product or service failures (Weiner, 2000; Folkes, 1984). In this study, we found that hotels guests' overall satisfaction and service quality assessments are higher when the guests believe that the service failure is unstable (i.e., unlikely to happen again in the future) and the service recovery is stable (i.e., likely to be similarly resolved should a service failure occur). Moreover, guests are more likely to return to the same hotel when they believe that service failure is unstable and recovery is stable.

\section{DISCUSSION, RESEARCH IMPLICATIONS, AND MANAGERIAL IMPLICATIONS}

Overall, many of our findings with actual hotel guests are consistent with previous work that employed student samples (McCollough, 2000). However, unlike previous research, we found that hotel guests are more satisfied with the upgraded guestroom when they perceive recovery as being stable rather than unstable. Further, unlike previous re- 
search in this area, our results indicate that stability attributions influence the guests' intent to return.

Due to the intangibility and inseparability of services like hotel accommodations, consumers' perceptions of satisfaction may include contextual cues that they use to evaluate quality and to decide whether to return (Choi \& Chu, 2001). Thus, the manner in which the upgraded guest room is presented to the guest may be a contextual cue used by guests to evaluate their satisfaction with the room accommodation itself. Seasoned travelers, who are likely to encounter overbooking in real life, seem to be sensitive to the hotel's ability to recover from service failures in a consistent manner. Our findings provide additional support for Barsky and Labagh's (1992) contention that the manner of guest reception is directly linked to return intent.

Service recovery strategies and tactics should be matched to the specific incident (Levesque \& McDougall, 2000). The subject study found that the optimal tactical match in the incidence of overbooking is that the guest ultimately needs to be convinced that service failure is unlikely, and in the rare instances when service failure occurs, that recovery is stable, e.g., in this case, that an upgraded room is almost always available. Ultimately, however, most hotel guests seem to be indicating that had they truly desired to have an upgraded guest room (a suite), they probably would have been willing to pay for it. It goes without saying that lodging managers should be attentive to their yield (i.e., overbooking should occur to the extent of no-shows and cancellations).

For practicing managers, this research provides some strategic direction regarding the handling of service failure and recovery, in general, and specifically regarding the common practice of overbooking. Strategic management is often discussed in terms of strategies and tactics (David, 2001). The strategy of concern in the subject study is hotel guest room yield management, i.e., revenue management. Essentially, a hotel manager may take either a conservative or an aggressive approach with respect to the strategy of revenue management. Based on the results of the subject study, hotel managers should be aware that if they take an aggressive approach regarding overbooking, there exists a strong likelihood that when the hotel fails to deliver on its promise to guests, the guests' entire experience (including their satisfaction with facilities) may be tainted, and the guests may even be less likely to return. As Levesque and McDougall (2000) ultimately concluded, "Getting it right the first time is the best strategy."

Since our research resulted in certain findings that are different from some previous research in this area, namely that service recovery tech- 
nique influences actual hotel guests' satisfaction with guest room accommodations, future research should seek to confirm these findings using actual hotel guests (as we did). In addition, future research should attempt to replicate our findings regarding hotel guest return intent because previous research in this area did not consider this variable. Further, future research could attempt to develop a multiple-variable measure of guest return intent, as has already been developed for the other major constructs considered by our study. Finally, future research should examine the causal links between stability attributions, guest satisfaction, and return intent.

\section{REFERENCES}

Barsky, J.D., Labagh, R., 1992. A strategy for customer satisfaction. Cornell Hotel and Restaurant Administration Quarterly, 33(5), 32-40.

Brown, S., 1997. Service recovery through IT: Complaint handling will differentiate firms in the future. Marketing Management, 25-27.

Choi, T.Y., Chu, R., 2001. Determinants of hotel guests' satisfaction and repeat patronage in the Hong Kong hotel industry. International Journal of Hospitality Management, 20, 277-297.

David, F.R. 2001. Strategic Management Concepts (8th Ed.), Upper Saddle River, NJ: Prentice Hall.

Folkes, V., Koletsky, S., Graham, J., 1987. A field study of causal inferences and consumer reaction: the view from the airport. Journal of Consumer Research, 13(March), 534-39.

Folkes, V.S., 1984. Consumer reactions to product failure: An attributional approach. Journal of Consumer Research, 10(4), 398-409.

Fornell, C., Wernerfelt, B., 1987. Defensive marketing strategy by consumer complaint management: A theoretical analysis. Journal of Marketing Research, 24(November), 337-346.

Johnston, R., Fern, A., 1999. Service recovery strategies for single and double deviation scenarios. The Service Industries Journal, 19(2), 69-82.

Levesque, T., McDougall, G., 2000. Service problems and recovery strategies: an experiment. Canadian Journal of Administrative Sciences, 17(1), 20-37.

Liu, C., C. Warden, C. Lee, Huang, C. 2001. Fatal service failures across cultures. Journal of Hospitality \& Leisure Marketing, 8(1/2), 93-113.

Mattila, A., 1999. Consumers' value judgments. Cornell Hotel and Restaurant Administration Quarterly, 40(1), 40-46.

McCollough, M.A., 2000. The effect of perceived justice and attributions regarding service failure and recovery on post-recovery customer satisfaction and service quality attitudes. Journal of Hospitality \& Tourism Research, 24(4), 423-447.

McCollough, M.A., Berry, L., Yadav, M., 2000. An empirical investigation of customer satisfaction after service failure and recovery. Journal of Service Research, $3(2), 121-137$. 
Miller, J., Craighead, C., Karwan, K., 2000. Service recovery: A framework and empirical investigation. Journal of Operations Management, 18, 387-400.

Mount, D.J., Mattila, A., 2000. The final opportunity: The effectiveness of a customer relations call center in recovering hotel guests. Journal of Hospitality \& Tourism Research, 24(4), 514-525.

Richins, M.L., 1983. Negative word-of-mouth by dissatisfied consumers: A pilot study. Journal of Marketing, 47, 68-78.

Rosenthal, R., Rosnow, R.L., 1991. Essentials of behavioral research: Methods and data analysis. New York: McGraw Hill.

Schumacker, R.E., Lomax, R., 1996. A Beginner's Guide to Structural Equation Modeling, NJ: Lawrence Erlbaum Associates.

Smith, A.K., Bolton R.N., 1998. An experimental investigation of customer reactions to service failure and recovery encounter: paradox or peril? Journal of Service Research, 1(1), 65-81.

Smith, A., Bolton, R., Wagner, J., 1999. A model of customer satisfaction with service encounters involving failure and recovery. Journal of Marketing Research, 34(August), 356-372.

Tam, J., 2000. The effects of service quality, perceived value and customer satisfaction on behavioral intentions. Journal of Hospitality \& Leisure Marketing, 6(4), 31-44.

Tax, S., Brown, S., 1998. Recovering form learning from service failure. Sloan Management Review, Fall, 75-88.

Taylor, S., 1994. Waiting for service: The relationship between delays and evaluations of service. Journal of Marketing, 58(April), 56-69.

Weiner, B., 2000. Attributional thoughts about consumer behavior. Journal of Consumer Research, 27(3), 382-387.

Weiner, B., 1980. Cognitive (attribution)-emotion-action model of motivated help giving. Journal of Personality \& Social Psychology, 39(2), 186-200.

Zemke, R., 1999. Service recovery: Turning oops into opportunity. In Best Practices in Customer Service (R. Zemke \& J. Woods, Eds.), AMACOM, AMA Publications, New York, 279-288. 


\section{APPENDIX}

1. Date

2. Name of interviewer

3. Name of interviewee

4. Address

5. Phone number

6. E-mail address

7. Interviewee sex (circle one number):

1 Male

2 Female

8. Interviewee Age (round to nearest year)

9. List the name and city of a hotel where the interviewee has stayed during the past year: Hotel/motel name Hotel/motel city/location

10. For each of the following questions, circle the one number that most applies.

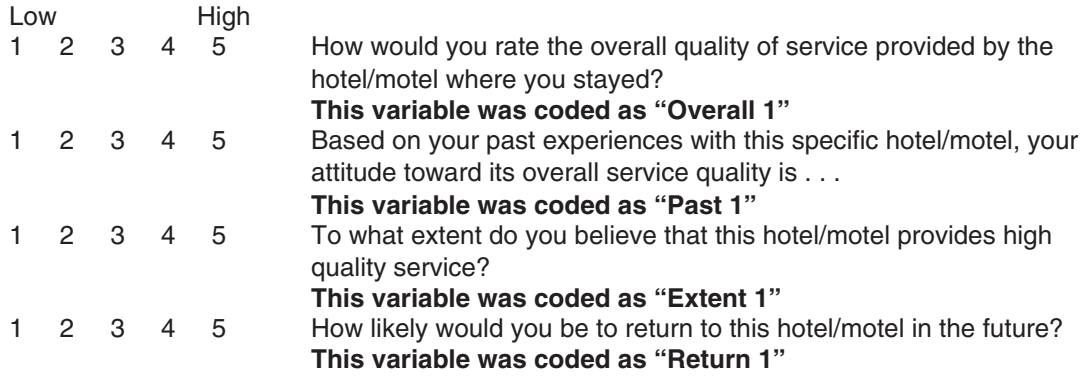

11. The interviewee should read the following information and complete the following questions:

Imagine that you are traveling and are staying overnight at the hotel/motel that you indicated above where you stayed in the past year. You made your reservation several weeks ago and have a confirmed, guaranteed reservation for a standard "economy" room with a double bed. You give your name to the clerk on duty at the front desk. The following dialogue then takes place:

Clerk: I'm sorry, but we're overbooked and don't have your reserved room. This almost never happens as we have a policy not to overbook, I can't remember the last time this happened.

The clerk looks very concerned and begins pushing buttons on his or her computer terminal.

Your response: Is there anything you can do for me?

Clerk: $\quad$ We rarely run out of rooms and are almost never full. So, if you'd like, I can upgrade you to our best room at no extra charge. It's a very nice suite with two rooms, a king-size bed, and a great view. Will that be acceptable?

Your response: $\quad$ Yes, that will be fine. 


\section{APPENDIX (continued)}

The clerk pushes some more buttons, prints out a registration card, and hands you a key. You notice that the registration is for a suite at no extra charge.

Clerk:

Again, I'm very sorry about the confusion. This rarely happens, so we don't usually have this problem. Please enjoy your stay, and let us know if there is anything we can do to make your visit more pleasant.

You thank the clerk and leave the desk area. Your room proves to be a beautiful, spacious suite with plenty of amenities, and you have no complaints.

\begin{tabular}{|c|c|c|c|c|c|}
\hline Lor & & & & High & \\
\hline 1 & 2 & 3 & 4 & 5 & $\begin{array}{l}\text { Given the situation you read, how would you rate the overall } \\
\text { quality of service provided by the hotel/motel where you stayed? } \\
\text { This variable was coded as "Overall 2" }\end{array}$ \\
\hline 1 & 2 & 3 & 4 & 5 & $\begin{array}{l}\text { Based on your past experiences with this specific hotel/motel, } \\
\text { including the events described, your attitude toward its overall } \\
\text { service quality is ... } \\
\text { This variable was coded as "Past 2" }\end{array}$ \\
\hline 1 & 2 & 3 & 4 & 5 & $\begin{array}{l}\text { Considering the event you read about, to what extent do you } \\
\text { believe that this hotel/motel provides high quality service? } \\
\text { This variable was coded as "Extent 2"' }\end{array}$ \\
\hline 1 & 2 & 3 & 4 & 5 & $\begin{array}{l}\text { How satisfied would you be with the room provided? } \\
\text { This variable was coded as "Satisfied" }\end{array}$ \\
\hline 1 & 2 & 3 & 4 & 5 & $\begin{array}{l}\text { How well did this room meet your needs? } \\
\text { This variable was coded as "Needs" }\end{array}$ \\
\hline 1 & 2 & 3 & 4 & 5 & $\begin{array}{l}\text { Overall, how satisfied would you be with the room? } \\
\text { This variable was coded as "Room" }\end{array}$ \\
\hline 1 & 2 & 3 & 4 & 5 & $\begin{array}{l}\text { How satisfied did this experience leave you feeling? } \\
\text { This variable was coded as "Feeling" }\end{array}$ \\
\hline 1 & 2 & 3 & 4 & 5 & $\begin{array}{l}\text { How well did this overall service experience meet your needs? } \\
\text { This variable was coded as "Experience" }\end{array}$ \\
\hline & 2 & 3 & 4 & 5 & $\begin{array}{l}\text { Overall, would you be very satisfied with this service encounter? } \\
\text { This variable was coded as "Encounter" }\end{array}$ \\
\hline & 2 & 3 & 4 & 5 & $\begin{array}{l}\text { How likely would you be to return to this hotel/motel in the future? } \\
\text { This variable was coded as "Return 2" }\end{array}$ \\
\hline
\end{tabular}

